\title{
Developing Short-Term Study Abroad Programs: Achieving Successful International Student Experiences
}

\author{
James Eckert, Western Michigan University, USA \\ Mushtaq Luqmani, Western Michigan University, USA \\ Stephen Newell, Western Michigan University, USA \\ Zahir Quraeshi, Western Michigan University, USA \\ Bret Wagner, Western Michigan University, USA
}

\begin{abstract}
Most business schools in the U.S. are employing various initiatives to "internationalize" their curriculum in order to prepare students to participate more effectively in a globally interconnected business world. An integral part of these initiatives is to encourage more students to participate in study abroad programs. Though it may be optimal for students to study abroad for a semester or more, many students do not have the time, resources or confidence to commit to a long-term experience. Consequently, short-term two to three week study abroad programs (SSA) are often a viable and worthwhile experiential alternative. Often, the process of developing a short-term study abroad experience can be daunting. We use a case study approach to examine how short-term study programs were initiated, planned, organized and implemented in five countries - Malaysia, Singapore, Chile, Germany and Australia. These programs were led by business faculty, at an AACSB accredited Midwestern University, each of whom also had prior experience in conducting study abroad programs. These faculty leaders provided detailed accounts related to each of the programs. A guide using probing questions was prepared through a triangulation process that included the faculty leaders and an administrator that had reviewed and audited 12 previous short-term study abroad programs. Drawing on actual SSA experiences and outcomes, this paper proposes a SSA framework consisting of planning, marketing, conducting and evaluating stages that can make the study abroad process understandable, efficient and easier to implement.
\end{abstract}

Keywords: Study Abroad; Global Business Education; Internationalization of Curriculum; Short-Term Study Abroad

\section{INTRODUCTION}

$\mathrm{n}$ an increasingly interdependent business world, students have to be prepared to work with and next to counterparts from different parts of the world and from different cultures. Not surprisingly, academicians and businesspersons in unison emphasize that universities should nurture global awareness and engagement in our students. The Association of International Educators (NAFSA, 2003) has continually in the last decade said that "Study Abroad must become the norm, not the exception, at higher education institutions (p.3.). We need to aggressively promote it to each rising generation". Businesspersons, academics and policymakers represented in The Lincoln commission (2005) emphasized that "Engagement of American undergraduates with the world around them is vital to the nation's well-being". AACSB requires schools to develop global perspectives among the various internationalization initiatives undertaken. The benefits that students can realize through study abroad programs have been widely articulated through various forums. A review of the literature provides representative studies, which document these benefits (see Table 1). 
Table 1: Benefits Of Study Abroad Programs

\begin{tabular}{|l|l|}
\hline \multicolumn{1}{|c|}{ Benefits To Students } & \multicolumn{1}{|c|}{ Source } \\
\hline Build cross- cultural awareness & Black \& Duhan, 2006 \\
\hline Develop personal identities, self-image & Black \& Duhan, 2006;Angulo, 2008 \\
\hline Nurture intellectual growth & $\begin{array}{l}\text { Carlson \& Widaman, 1988; Carlson, Burn,Useem, \& } \\
\text { Yachimowicz,1991; Hutchins, 1996; McCabe,1994;Thomlison, 1991; } \\
\text { Drews \& Meyer, 1996 }\end{array}$ \\
\hline Enhance intercultural competence & Hilton, 2007; Clarke, Flaherty Wright \& McMillen, 2009 \\
\hline Develop effectiveness in Cross-cultural interactions & Clarke, Flaherty,Wright \&McMillen, 2009 \\
\hline Develop initiative and adaptability & Curran, 2007; Norris \& Gillespie, 2009 \\
\hline Help Understand own cultural biases & $\begin{array}{l}\text { Gammonley, Rotabi, \& Gamble, 2007; Langley \& Breese, 2005; } \\
\text { Milstein,2005; Mistretta, 2008; Williams, 2005 }\end{array}$ \\
\hline Lessen ethnocentricity & Carlson \& Widaman,1988; Kitsantas,2004 \\
\hline Reduce prejudice, accept alternative viewpoints & Carlson et al.,1990; Golay,2006;Hadis, 2005 \\
\hline Facilitate understanding of global issues & $\begin{array}{l}\text { Carlson et al., 1990; Carsello \& Creaser,1976; Golay,2006; } \\
\text { Gonyea,2008 Schuster et al.,1998 }\end{array}$ \\
\hline
\end{tabular}

In 2009-2010, about fifty-five thousand business students, comprising $20 \%$ of all U.S. students, studied abroad (Institute of International Education, 2011). Many business colleges are encouraging students to participate in study abroad programs. Studies focusing on conducting study abroad programs for business students are sparse. Moreover, these have focused more on the motivations and concerns of business students and faculty leaders as they relate to participation in such programs; fewer studies provide specific guidance on organizing and conducting programs that can help realize the benefits, particularly through short-term (two- to three-week) programs that many colleges of business want to offer to their students (e.g. Quraeshi, Luqmani \& Veeck, 2012; Kaufman et al., 2011; DeJong, Schnusenberg \& Goel, 2010; Koernig, 2007; Toncar, Reid \& Anderson, 2005; Duke, 2000; Toncar \& Cudmore, 2000; Albers-Miller, Prenshaw \& Straughan,1999; Brokaw, 1996).

\section{PURPOSE}

The objective of this paper is to provide a systematic framework and steps for planning, organizing and conducting short-term-study abroad programs (SSA). Such a framework can provide guidance to faculty and administrators, particularly in business schools, as they initiate and aim to improve the quality of their short-term study abroad program offerings.

\section{SHORT-TERM STUDY ABROAD PROGRAM FRAMEWORK}

Developing a SSA program is somewhat long and complex. For the purposes of this paper, we have developed a framework that breaks this process down into four stages: 1) Planning; 2) Marketing; 3) Conducting and 4) Program Evaluation (see Figure 1).

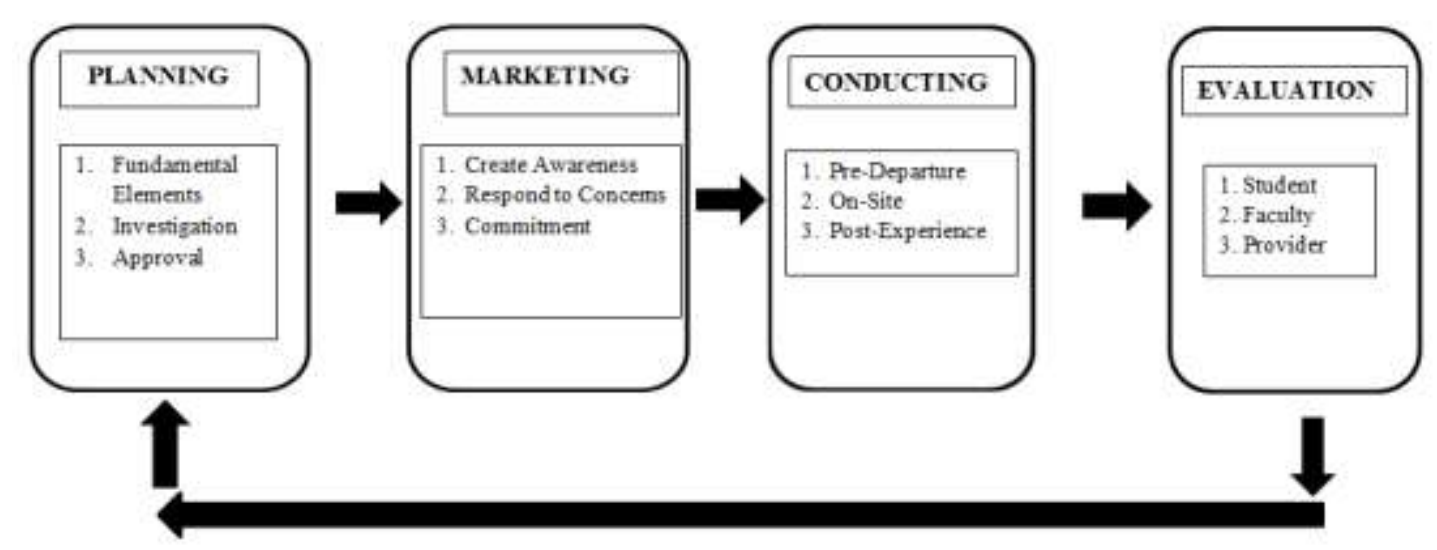

Figure 1: Steps In Developing A Short-Term Study Abroad Program 


\section{STAGE 1: PLANNING}

Planning a SSA is a significant undertaking that can quickly become an overwhelming struggle without proper resources and a good planning process. An initial understanding of the issues that one will need to address will make the planning process more manageable. There are three broad general stages to the planning process for a SSA program. They include: 1. Nurturing Program Elements; 2. Investigation of Potential Program; and 3. Final Approval.

\section{Nurturing Program Elements}

As a starting point for developing an effective SSA program, five questions must be considered. First and foremost, is there a faculty champion willing to spearhead the program? Second, should the program be selforganized, provider-organized, or a hybrid approach? Third, how will the program be integrated into the existing curriculum so that it is a part of a student's academic program? Fourth, will there be institutional buy-in? And lastly, are adequate resources available for preliminary planning and implementation?

\section{A. Is There A Willing Faculty Champion?}

Having a faculty champion with existing contacts and passion for the area of study is a very critical factor for the success of the trip. Students often gravitate toward a particular program because of who is leading it. This is strongly supported by our experience with study abroad programs. Hence, the faculty member needs to have a good relationship with students and be able to sell the program to them, while students must feel that the program is being run by a professor with whom they would like to spend a significant amount of time. Moreover, the faculty leader needs to convey his/her enthusiasm to potential participants. Our Japan/Thailand trip's popularity is connected to the passion and vast experience of the faculty director whose background is from the area and makes our students readily enter into this program. Since the faculty champion guides the program throughout the process, he/she has to devote considerable time, effort and attention to detail to develop a beneficial program. The champion must be prepared to cope with unexpected events that can occur before and during a SSA. For example, in our Malaysia program in summer 2011, we had to make timely changes because of political strife and demonstrations that occurred spontaneously while we were there. Changes were implemented because there were plans in place for such unexpected occurrences. A similar situation occurred with our Japan/Thailand trip in 2010 when protests by the "Red Shirts" led the study abroad office to decide that Bangkok should be avoided on the trip. This was a significant problem given its importance as the capital and largest city in Thailand. However, the faculty champion's experience as a native Thai allowed him to quickly make alternate arrangements and keep the trip relevant and educational. On the other hand, the faculty champion's commitment to offer a dedicated program is influenced by a variety of considerations, including the recognition and value given by the administration and faculty colleagues on his/her contribution, adequate and competitive compensation offered to plan and conduct the program, and whether the study abroad program is considered as part of the regular teaching load or as an overload.

\section{B. What Organizational Approach Should Be Used - Self, Provider, Or Hybrid Organized?}

One of the key early decisions for the faculty champion is as to who will organize the program. Programs can be put together using a range of methods. At one end of the spectrum is a fully "self-organized' approach where most of the initial investigation, logistical issues, and personal contacts are largely driven by one or more faculty leaders. This is a more demanding process and should only be used if the faculty leader has academic and business contacts in the host country or has a network of local contacts that can provide assistance, particularly with scheduling business visits. In our experience, organizing and scheduling the in-country business visits is the most difficult component of program organization. Cold calls and requests to companies and organizations overseas rarely worked because many of these companies are increasingly inundated with requests from the U. S. The best results are achieved through personal contacts at home and abroad. Our experience is that a company's willingness to support a visit is largely dependent upon the faculty leader's professional and personal relationship with these individuals connected to the organization. We have used the self-organized process for two programs we conducted in 2011 and 2012 to Malaysia/Singapore and Germany. In both cases, the faculty champion relied on his academic and business contacts to help arrange the business and organizational visits. 
At the other end of the spectrum are "provider-organized" programs where all organizational work is taken care of by a third party, usually located in the region that the program is centered. This can be a good option if there is little institutional experience in short-term program plans. If a faculty member has never been on a SSA program, this option would be best. Most programs will ultimately end up somewhere between these end points using a hybrid approach. For instance, while our Germany trip is mostly self-organized by our faculty champion, he does rely on our German university partner to arrange some of the accommodations and activities. Additionally, while our Chile program was mostly provider-organized, the faculty champions helped shape the trip through their interactions with the provider during the planning process. The faculty champion can elect a range of support from the study abroad provider. Providers can offer complete programs organized so that little work is required of the faculty champion in planning details or executing the program on-site. If the faculty champion has had SSA experience, a good option for providers may still be to arrange the logistics - primarily housing and transportation - while having the faculty champion plan the academic components such as partner university activities, business tours, and cultural visits. Frequently, a good provider can better estimate costs such as facility reservations, accommodations and logistics (especially when there are different time zones), use its buying power and connections to lower overall costs and simplify billing and payment whereby multiple cost items can be put on a single invoice. Furthermore, a good provider ensures that the quality of service remains high.

Another option is to use a partner university as the study abroad provider. If there is a strong relationship with the partner university, many of the provider services may come at no cost. With our Australia program, it was first self-organized and, while successful, the workload of organizing plans was significant. Later, the program was run again with a commercial provider handling the major arrangements for the week in Sydney and a university partner handling the week in Melbourne. Our experience was that this approach provided higher-quality accommodations and logistics than prior trips at the same cost. In addition to assistance with business visits, academic partner universities and faculty counterparts can help organize both academic based activities and cultural experiences. In our Germany program, we partner with two different German universities to do day-long marketing and negotiation case analyses, where teams of visiting and host university students compete to present case solutions and to enable intercultural exchange while faculty from both universities serve as judges. Both universities benefit from the academic exercise and the cross-cultural exchange built into the experience. Local faculty contacts can help arrange both formal and informal cultural experiences. Formal cultural experiences have included visits to cultural heritage sites, museums, local bazaars, etc. The in-country faculty colleague can help point the group to interesting cultural and historical sites that might not make the list of top tourist destinations but would provide more interesting and authentic experiences. Lastly, academic colleagues can help arrange for local students to meet and interact with the visiting students, both formally and during free time. This model has worked well for us in multiple programs as the student hosts have helped expose our students to authentic local culture and cross-cultural differences. Many of our students remain in touch with these students through Facebook and LinkedIn, thus creating a valuable network for themselves. Besides the faculty champion's network, other sources of help in organizing business visits include executives of companies in the U.S. who have subsidiaries/affiliates in the host country, executive alumni in the host country, U.S. commercial attaches, U.S. Department of Commerce Export assistance center and joint chambers of commerce in the country (e.g. U.S. - Singapore).

On the other end of the spectrum, our 2012 program to Chile is an example of a completely providerorganized program with very positive results. We wanted to provide the short-term study abroad opportunity in South America in 2012, a region where we had not gone before. The faculty leaders did not have academic or business contacts in Chile, but students had regularly voiced their interest in such a program. The dean of the college had been approached by the provider at a conference and, after talking to counterparts who had used the provider's services, she recommended that we explore utilizing this provider. The provider specializes in organizing study abroad programs only in South America and has numerous business contacts with both private and public organizations. This provider had a very professional approach to our needs and expectations and did an outstanding job. 


\section{How Will Academic Integration Be Achieved?}

Study abroad courses should be considered a vital part of the student's academic program and that they count toward the student's graduation requirements. In the long run, it is desirable to have the short-term study course be at least an elective option in the student's academic program. This can be facilitated further if academic advisors have the ability to substitute the credits from a short-term study program for another course requirement. Such flexibility not only reduces the administrative burden in student advising, but having the course "on the books" and an option in the student's academic program serves as another appealing factor and form of promoting a SSA.

\section{Is There Institutional Buy-In?}

Institutional buy-in is necessary at two levels - college and university. First, there is a need for a shared vision to improve global business and cross-cultural awareness and global engagement for students. These are articulated goals of our university and college that are continuously underscored to the university community and significantly supported at the highest levels, allowing us to expand our SSA offerings. Without this in earlier times, short-term SSA programs were offered only sporadically. Now we offer a variety of such programs. At our college, most study abroad program proposals are presented by interested faculty to the IBEC (International Business Education Committee) which reviews them to see whether there is sufficient diversity between country sites, while paying close attention to the safety of the site for students. For example, at least one country proposal in 2012 was tabled for future consideration because of security issues. The university follows with a review by our centralized university international office which generally endorses and supports college-initiated proposals.

\section{E. Is There Funding For Preliminary Planning And Investigation of SSA?}

There are a few typical costs associated with planning and/or investigating a new SSA. These include advance visit funding and "faculty champion in-training" funding. Funding is often required to visit the SSA site as part of the planning process. In some situations, an initial proposal for funds to go on a preliminary site visit must be written and approved by the administration of the college or university. At our university, the deadline for the proposal for the preliminary visit is over a year in advance of the actual trip. Funding of these visits may be divided between the university study-abroad office and the college sponsoring the program, as is done in our university. Another potential in-advance cost for a new SSA is to send the potential faculty champion on an existing SSA program. This allows the faculty champion to see the day-to-day workings and challenges of a SSA program. While this is a good idea, it requires that either the existing program has funds to bring along this in-training faculty champion or the college or university must provide the funds to allow this to happen. As our college has four existing programs each year, we try to identify future faculty champions and bring them along on these existing programs. This not only solves the training issue but also provides a second faculty member for the trip, which is highly advisable. The second faculty member is also available to act as a resource and back-up to the primary faculty champion.

\section{Investigating Program Specifics}

A more formal evaluation needs to be undertaken after the fundamental elements of the proposed program have been agreed upon by the relevant parties (faculty, committees, dean, study abroad office, etc.). It is important to note that the culture in many countries is such that phone and email interactions cannot effectively be substituted for face-to-face interaction. Critical program specifics include location choice, itinerary, and financial budget.

\section{A. Location Choice}

Having a partner university at the study abroad location has a number of benefits and a list of these partner universities can be a good starting point for identifying SSA locations. Faculty members with an interest or background in an area influence choice. Locations may also be recommended by administrators at both a college and/or university level to help achieve other administrative goals or objectives. Feedback or suggestions by students and their interests are often the basis for new program discussions. It is also important that the location is somewhere the targeted students want to go. Student demand for programs needs to be taken into consideration. As 
our university is a regional state university, the students tend to be drawn regionally. They have had more modest upbringings, are often from smaller towns, have little experience with travel, and most often do not speak another language well. These circumstances have led to increased demand for places that might be perceived as safe and easy choices (e.g. Australia, Germany, France, etc.). Other university settings may offer a different set of circumstances. The college through which the program is organized may influence location choice. For example, students in our College of Business tend to seek out places where business learning makes sense. These students tend to be more main stream than perhaps their liberal arts colleagues and seek pragmatic choices. For example, our Australia and Germany trips are very popular. Safety considerations will have an impact on selecting the destination. There are many challenges in putting together a program and dealing with political instability is a challenge that is good to avoid. However, this is not always so easy. The 2004 Madrid bombing had an impact on short-term programs as many students and parents became concerned with travel to Europe. Similarly, the Red Shirt riots in in Bangkok have caused us to modify our trips to Thailand. It is important to have good local knowledge when assessing risks. In some cases, organizations that provide travel information do not provide an accurate picture of the true situation. Many times these organizations merely pass on news stories which may not portray an accurate picture of what is really happening on the ground. For example in the 2010 Thailand riots, the violence only involved an area of a few square blocks in a city of 8 million people, but was presented by the press as if it engulfed the entire city. In reality, travel to Bangkok during this time was quite safe as long as travel to those few blocks was avoided. While local knowledge may provide a better understanding of the true risks for international travel, perception undermines reality in these cases. If students and parents become concerned by news reports of potential safety threats, then it does not really matter what the actual situation is on the ground. While it is difficult to predict where trouble may occur, it is good to gather as much information on the potential issues with the destination site. It is also good to stay in contact with the university's study abroad office to keep abreast of potential security issues.

Whatever the recommended location, a faculty champion must exist for the SSA. This consideration is impacted by the culture for study abroad. If there are already a number of short-term programs that are regularly offered and the awareness of study abroad opportunities is strong, then a study abroad trip to an "exotic" location like Vietnam or Cambodia - may be successful, but if there is little in the way of a study abroad culture and this is going to be the first short-term trip in the educational unit, then a more "traditional" destination may be in order. Next, locations for SSA programs need to be whetted and discussed. This must often be done in conjunction with an evaluation of potential lodging, businesses, cultural sites, as well as other logistical issues. A personal visit to the location (usually by the faculty champion), particularly when the program is self-organized, is an essential part of planning for a SSA. Specifically, the leader has to have a personal understanding about the logistics of the trip. Transportation options (to and from the train/airport, as well as between company and cultural landmarks) need to be experienced to better understand possible problems. Also, negotiations with cultural, government and business representatives to set up arrangements are best arranged in-person.

\section{B. Itinerary}

The itinerary is a key planning document for a study abroad trip. It should detail what the trip will accomplish. It is not possible to begin planning without a preliminary itinerary. The itinerary will start with preliminary dates for the trip and activities as available. Usually the dates are based on the university calendar. Many of our study abroad trips begin soon after spring semester ends. For our Australia trip, we move this forward by a few days to take advantage of lower airfares that begin May 1 . The next thing to look at is where weekends and holidays fall. Usually it is a bigger challenge to find academic activities during the weekend, so weekends are potentially good times for in-country travel or cultural activities, but again, the weekends will usually have larger crowds as well. Holidays can create significant challenges and should be explored very early. For example, one year we planned a two-week trip that included London and Paris. Our original plan was to start in London and then move to Paris, but because of French holidays, we decided to start in Paris first. This was fortuitous and we realized later that students would have been much less enthused about Paris if they had visited London first. In general, the itinerary should be like a fireworks show - finish with the grand finale. For example, we have switched our Australia itinerary to start in Melbourne rather than Sydney. While both cities have great features, Sydney does have more visual beauty and is warmer (we travel during their fall season). Students tend to appreciate Melbourne much more now. The students are ending a semester and arriving after a long plane ride and are excited with their first experience in Australia. Some students now prefer Melbourne over Sydney, seeing its easier pace and livability 
as a major plus.

Another itinerary factor to consider is variety. Generally, you want to add variety to the trip so that the students find uniqueness and that it doesn't just feel like the same thing over and over. For instance, scheduling three days in a row of company visits could become tedious, whereas those same three days spaced out would be well received. Our Germany program has a three-day stretch where the first day is all day at VW World Headquarters, day two is a university-based case experience with the faculty and students at University Potsdam, and the third day is a day-long bike tour of cultural sights in Berlin. Moreover, the itinerary should be viewed as a key piece in a design spiral. There is an initial itinerary, followed by checks against the calendar and holidays. This is followed by creating a budget, which may result in changes to the itinerary to reduce costs, for example. Contacts in the study abroad location may suggest other activities which may create changes to the itinerary. This continuous process of revision and refinement is best driven by an itinerary. The itinerary can also serve as a useful communication tool for students who are interested in the trip. It is never easy to explain the full experience to prospective students, but an itinerary gives them a very good picture of what will happen on the trip. Students also share this itinerary with parents as well. Hence, an effective itinerary for promotional purposes will include dates, key activities, and pictures of sites that will be visited.

\section{Financial/Budget}

A detailed breakdown of the costs involved in the program needs to be prepared. The first step is to determine what requirements the university will put on the trip's budget. Key costs that can be determined up front are student costs such as tuition, fees, and insurance, that must be included as part of the program. Next, the costs for the SSA leaders must be determined. This includes pay or stipends, transportation, program costs, meals, and incidentals. These costs form the majority of the fixed costs of the program. It is useful to develop a simple spreadsheet outlining program costs against the number of students in the program. Because the fixed costs are typically fairly significant, the cost per student is affected by the number of students on the trip. In our experience, on average, a minimum of 15 students is required to make the program financially viable. As the number of students increase, the per-student costs will drop. There is a temptation to shoot for a large program size to make the program affordable, but that creates three problems. First, for every student you add to the program, you add a large number of interpersonal interactions that could prove problematic. For example, if you have 15 students on the trip, adding one student means there are an additional 15 student interactions that could prove to become a problem. Student dynamics are an important consideration on the trip and more people create more challenges. Second, large groups are more unwieldy. They are harder to assemble and move around. On tours, there may be too many students to effectively hear the tour guide. Finally, if the trip is budgeted and priced on having a large number of students participate and the recruiting process falls short, the faculty champion may be faced with the unpleasant problem of increasing the program fee to break even. If the price is set on a smaller number of students and more students are accepted into the program, then additional meals or activities can be added. It is always better to under-promise and over-deliver. In addition, out-of-pocket expenses need to be estimated and provided to students so they can understand the "true" cost of the program. These may include extra meals and airplane fees (if not part of the official program), passport fees, visa fees, extra excursions, and other miscellaneous costs.

\section{Final Approval}

The final program proposal, including financial details, needs to be written and submitted to the appropriate individuals at the university. In many institutions, this has to be approved at multiple levels, including department, college, and university. It is often critical to understand the approval processes before the planning process is started so that appropriate milestones can be met. After the proposal has gained the support of the administration, the marketing of the program begins.

\section{STAGE 2: MARKETING}

Once the proposal has been formally approved, the task of marketing the program to students should be the focal point. Marketing, to a significant degree, rests with the faculty champion. All of the communication approaches and events do not add up to the value of an involved and passionate faculty member who is willing to 
interact and recruit students. Faculty champions must be comfortable with this role to attract enough students to make the program viable. The marketing process for a SSA can be broken into three steps: 1) creating awareness and interest for the SSA, 2) responding to student issues/concerns, and 3) gaining commitment.

\section{Creating Awareness And Interest For The SSA}

The first step is to create awareness among student of the programs that are offered. A variety of materials, disseminated through multiple channels, can increase student interest and demand for the SSA.

\section{A. Type Of Information Materials}

A good flyer/brochure is a good starting point for communicating program details to students. Basic information that is useful to include in a flyer is an itinerary, program cost, deadlines for application, and dates for pre-departure meetings. However, though the flyer should be informative, it should not be too detailed. An electronic form of the flyer is also very useful to provide to students so that they can send it to parents to gain support for participating in the program. For an established program, electronic marketing materials (websites, blogs and short videos) have been shown to be very effective.

\section{B. Dissemination Of Information}

The processes mentioned above are complemented by other efforts, such as where the faculty champion, or other study abroad representative, visits certain key classes, particularly the large auditorium classes. Short PowerPoint presentations on the program can also be useful in stimulating student interest and providing follow-up information. Faculty champions do not simply promote their own programs but also let students know of others available. We find that it is the new site offering that requires the greatest marketing effort and faculty leaders try to provide encouragement for a program to a new site. Presenters should pass around a signup sheet to gather e-mail addresses for interested students for follow-up marketing. Another forum to create awareness and interest in university-wide study abroad programs is through University Study Abroad fairs. These target students at different levels - freshman to senior - at the undergraduate level and graduate students and reach students who are not in the College of Business but who may be eligible to participate based on their curriculum. One problem with the University Study Abroad Fair is that there are too many options. Students are frequently overwhelmed with the number of programs that are offered.

Another forum for dissemination of SSA materials is in the College of Business itself. Our college usually holds this event in the second week of October as a means to reach out to business students. This is organized as a day-long event with free Pizza and located off a high-traffic area. Study abroad opportunities are relayed to them during these events. In addition, the college now has a mandatory orientation for all those accepted into the College of Business. One component during this orientation, in keeping with the college's articulated goal of global business and cross-cultural understanding, is encouraging participation in study abroad programs and includes a presentation of different College of Business study abroad opportunities along with financial aid and scholarship support available to students. The students are encouraged to visit the Global Business Center at the college for more information and greater detail about these programs. With the College of Business program, there are usually three to four SSA programs and six to eight semester programs that are featured. The event is staffed by faculty and students who have participated in the programs, as well as from the study abroad and financial aid office. By focusing on a smaller number of business-related programs, students are not as overwhelmed by options and can get more integrated information about how the programs will fit with their academic programs. We found these business-specific study abroad fairs to be particularly effective in marketing SSA programs and in getting earlier registration of students for these programs. The latter becomes critical as go/no go decisions have to be made based on the enrollment in the SSA program. The most effective messages during the fair are those communicated by students who have been on prior study abroad programs. We ask these students to be candid in sharing their experiences overseas - good and bad - so that potential participants have a reasonable understanding of what to expect. Potential participants tend to place the most weight on word-of-mouth messages from their peers. 


\section{Informational Networks}

The use of email and social media to keep the students informed about the programs is vital in today's technology-centered world. During the first year of our Germany program, the faculty champion worked with the college's advising office and sent numerous email blasts to targeted students. Even after the program achieved "established" status, email blasts have continued to be an effective tool. Generally, emails encourage the student to respond in order to get more information and to be on an "interested student" list. Thus, the original email blasts are really designed as an opt-in approach designed to create a targeted list of interested students who then receive regular updates on the program. In addition to email, social media, such as Facebook or Twitter, can be used. For instance, our Germany faculty champion posted multiple Facebook updates and created multiple tweets encouraging his network to make contact if they were interested in the program. Similar to the email blasts, these efforts were designed to create a targeted list of more interested students to be used later to fully market the program. Lastly, a Facebook page can be made for the program and can act as a multifaceted marketing vehicle that includes descriptions, photos, videos, and student comments on prior SSAs. It can also be a way to link the participants from multiple years and create a great word-of-mouth resource. Our experience is that these social media efforts really hinge on the technological savvy and energy possessed by the faculty champion, unless the college itself is willing to have their social media manager create and manage these efforts on behalf of the SSA programs.

\section{Personal Meetings}

Personal meetings with faculty and students who have studied abroad in the past are a significant part of getting students to sign on to a study abroad program. In addition, another key influential group is the curriculum faculty and staff advisers. Ideally, a study abroad program should be included as an option that can fulfill curriculum requirements. In many schools, SSA programs are either offered as electives or as substitutes for courses offered. In registering for courses, the unknowing undergraduate or graduate may remain unaware of this alternative unless advisers routinely bring it to the attention of students and encourage their participation.

\section{E. Word-of-Mouth}

Highly critical to the marketing of a program is the word of mouth marketing from past students. For our long running programs - like Japan/Thailand, Germany, and Australia - it is easy to get the word out via past students and this level of marketing is often the most influential. This can be guided and encouraged by the Faculty Director by creating opportunities to connect students and by also asking and encouraging past participants to spread the word. For first-time programs, or even programs with a one- or two-year lull, using word of mouth can be a problem as few past participants remain to endorse the program. In such cases, using past students from a different trip can help somewhat, but, more likely, the marketing will have to be done through other mechanisms. For instance, our Germany program drew 28 students in its first year, but after a four-year pause, the program was four students short of its goal of 20, even though the number of emails, posters, info sessions, and class presentations was significantly increased. In the world of a university, a four-year pause is like never having the program as almost all previous students have graduated and there is no existing momentum. Now that the program has been running regularly for three years, there is a waiting list for participation in the program and much of that can be attributed to word-of-mouth.

\section{Responding To Student Issues/Concerns}

Once students have been exposed to the information about the SSA, they often have concerns about pursuing the study abroad opportunity. The more effectively these concerns can be identified and addressed, the greater the likelihood of participation. The most common issues fall under three major categories: 1) costs/affordability of the program, 2) course equivalencies and graduation delays, and 3) parental buy-in.

\section{A. Costs/Affordability Of Program}

SSA programs are not cheap and affordability is often a significant issue. Financial aid and its availability need to be conveyed to students, including the logistics of applying for scholarships, grants, loans, and other 
monetary help. For example, creating ready-to-go budgets that students can capture, print and bring to discuss with the Financial Aid officers help to make the process less daunting for the student. In addition, working with the Financial Aid office and keeping them abreast of the SSA program prepares them to better handle the financial needs of students. Simplifying the scholarship process can be extremely useful in marketing the program. Our Business School has collaborated with our University Study Abroad office to simplify the scholarship message. We are now able to say to prospective students that they will receive a $\$ 1,000$ scholarship for the program, whether it is granted by the Business School or the University Study Abroad office. This greatly simplifies the discussion of program costs with students.

In discussing the SSA cost with students, it should also be stressed that a significant portion of the trip involves out-of-pocket costs that would be incurred regardless of whether the student went abroad or not. For example, the cost of the credits for the embedded classes simply replaces the costs for equivalent course credit costs taken at home. In fact, they may be lower, as is the case at our university where SSA students are given stipends to support portion of the tuition. Some of the costs of in-country transportation and food correspond to the existing costs of filling the car up with gas, grocery shopping, and visits to local restaurants. Our Germany trip is a threeweek, six-credit trip with total costs, including spending money, estimated at $\$ 7,300$. After you subtract the $\$ 1,000$ scholarship, the $\$ 2,100$ cost of course credits and fees, the $\$ 50$ in gas you won't buy, the $\$ 150$ in grocery bills, $\$ 100$ in restaurant bills, the $\$ 200$ in social activities they won't have, and other such costs, the trip's actual costs discounted for these expenses may amount to $\$ 3,500-\$ 4,000$.

However, the best way to make programs affordable is to reduce the actual costs of the trip. There are different ways in which this can be accomplished. For example, for travel to the site and back, our programs have used different approaches. In Australia, the program provider works with a travel agency to provide a group ticket option that includes all flights from start to finish, lowering trip costs. Nearly all students on the Australia trip chose this option. Students like to travel as part of the group, and unless a student can use frequent flyer miles or has a relative who works for an airline, this is often the cheapest option. For our program to Chile, we provided a core airline itinerary and let students use other alternatives, such as using frequent flyer miles, discounted fares, and the like, to get to the site on the start date of the in-country program. In our Germany program, no group itinerary is arranged and students are encouraged to find their best value fare on their own. However, for certain sites, charter airlines can provide a cheaper travel alternative for students depending on the travel season. In-country transportation costs may also be high if the program requires significant travel within the host country, as is the case with our Germany program which schedules visits to six cities over two weeks. However, lowering such costs needs to be balanced with making the trip the best possible cultural experience. For example, the Germany trip experimented with a charter bus which saved money but hurt the cultural engagement of the trip; thus, the trip has returned to using the German rail system as the primary form of in-country transportation. Using pre-purchased train passes allows the costs to be reasonable while giving students a more culturally engaging experience.

Accommodation costs can range widely when a single overseas program provider is not used. Overseas academic partners have helped us in our programs by suggesting different housing arrangements, including using dorms, hostels, and hotels. Notably, local institutions often have agreements with hotels for such group visits, providing heavily discounted rates. We have also used a self-organized approach effectively for accommodations for trips where we have had long-term experience. For instance, the faculty champion for the Germany trip has always made the hotel/hostel accommodations himself. This has involved many emails and a great deal of web search time, but the advantage has been finding quality accommodations well suited for the group and in alignment with the trip goals, as well as in negotiating cost effective rates. If you use this approach, it is highly encouraged you contact the hotels directly via email or phone so as to negotiate the best rates and to build a relationship with the proprietors. This model has benefited our Germany program where proprietors have helped with upgrades and food arrangements (e.g. special welcome meal on the first night included in the rates) and suggested local activities and places to visit.

For meals (including those that are not covered by the single provider), our academic counterparts - and also the single provider - can provide helpful suggestions on the variety and prices of local foods available in proximity. In our program to Chile, Malaysia, and Singapore, we provide a set amount of money to each participant at each venue, encouraging them to try out local food at recommended (hygienic) places. A particularly beneficial 
process that we have used is to have host country students at partner universities interact with our participants on the first day of the program and to provide them with city tips, including student-favored eating joints that provide both value and experience. For the Australia and Germany programs, students are housed in apartments with kitchens during parts of the trip, allowing the students to "eat-in" and thus reduce meal costs.

Similarly, for recreational trips during free time - both covered and not covered by the program - a variety of alternatives can be suggested by the single provider. This works better than trying to organize the same recreational trip for all because of diverse interests. For example, in the Malaysia/Singapore and Chile program, we had at least three alternatives they could choose from and each with varying costs. For Australia, some of the "free" time was devoted to a leadership activity, where students were placed in groups of four with one member designated as the leader. The groups were given a list of places to visit - some free and some with fees. The group was to decide where to visit and the leader was advised to be sensitive to students' budgets. Students found these activities more effective in making use of their "free time" and resulted in their bonding with other group members. A similar "scavenger hunt" approach has been popular and educational for the Germany and Chile trips with students giving presentations on their experiences and lessons learned during the final celebration dinner.

\section{B. $\quad$ Course Equivalencies And Graduation Delays}

Advisors and faculty need to ensure that students get the requisite SSA course credits. Often students will need substitutions or creativity to allow for the SSA to fully count toward their graduation requirements. Students taking SSA should not experience graduation delays. When reasonable exceptions become the standard operating procedure, the success of the program is enhanced. Program directors should be aware that when these exceptions must cross college (and thus campus culture) boundaries, there could be less success. For instance, our SSA programs have not been approved to replace the general education requirement for an "other cultures" class, even though the participants will actually place themselves in another culture during the experience. This problem may be a result of campus politics and differences in perspective between the Business School and the more liberal artsoriented areas within campus.

\section{Buy-In (Parents And Students)}

This can be a major barrier to student participation. This is a bigger concern for college students who have a very close relationship with their parents or who are funded by them. Faculty advisors should be willing to speak to students and parents alike about the concerns parents might have. Hence, careful attention should be given to the messages the parents need to hear. We have found that safety remains the number one concern, but so is ease of communication. It is important also that advisors establish frequent communication with students and, whenever possible, with their parents. Even being out of contact for more than a few days is considered a large problem for many of the students/parents. Discussions of internet connectivity, cell phone use, skype, and other such technology is essential for easing parental and student concerns.

\section{Gaining Commitment}

Once objections and concerns are addressed, the final stage is to have the student officially sign up for the program. Making the procedure as easy and straightforward as possible will help to increase the number of students who ultimately participate in the program. When a student makes signs up for a program, there should be a financial stake involved. This gives them "skin in the game" and makes their commitment more serious. A past Australia SSA trip had 40 students informally sign up, but when the time came to formally commit to the program, only 16 of the students actually followed through and participated in the trip. Currently, students are assessed $\$ 300$ when they sign up, if the student backs out of the trip, they lose their deposit. This modest fee has reduced our dropout rates. The most common reason for the students to drop out, after initially committing, is financial. It is recommended that students be required to have a financial aid office appointment before the final commitment date. Late drops from the program are problematic for both the other students and the faculty organizing the trip, so every effort to ensure that those in the group are truly committed should be made. For the Germany program, only when the students purchase their airline ticket do we count on their participation. This action has proven to be a near perfect indicator of program commitment. 


\section{STAGE 3: CONDUCTING}

Based on the case studies of the short- term study abroad programs that we have conducted, we suggest a series of steps to help organize and conduct such programs. These activities can be broken down into three areas: 1 ) pre-departure activities and issues; 2) on-site activities and issues; and 3) post-experience evaluation.

\section{Pre-Departure Activities And Issues}

A number of issues have to be addressed; these can be divided into those which involve the students and those which are largely administrative that the faculty leader needs to take care before leaving on the excursion. Predeparture considerations include student-related factors, program orientation and culture, health and safety issues, behavioral issues, and logistics.

\section{A. $\quad$ Student-Related}

We have found that the vast majority of SSA students have never traveled abroad before and the more information they know about the international travel and the country they are visiting prior to departure, the better they will adjust and the more they will take from the experience. Hence, we require students to meet with us in order to prepare them for the SSA experience. Students also need to be advised on how they should obtain money abroad. Parents who have not recently traveled internationally may advise students to take traveler checks or cash. Students need to be advised that credit cards and ATMs are often better ways to make purchases or get cash overseas and that cardholders should be informed of their travel plans to avoid a hold on their account. Also, a method of effectively communicating with SSA students should be developed. For the Japan/Thailand trip, an inexpensive cell phone is included as part of the Thailand portion of the program for each student, while for the Australia trip, a cell phone for each group is provided. Students should be provided with business cards with the address of their accommodations upon arrival at each new site so that they can find their way back if they become lost or separated.

\section{B. $\quad$ Program Orientation And Culture}

Common to all our programs, orientation meetings are mandatory for all participants. At the first orientation meeting, the itinerary of the trip is reviewed. A course syllabus is distributed with expectations on course readings, assignments, research papers, participation requirements, deadlines and the like. For example, in our programs to Chile and Malaysia/Singapore, students had assigned readings about the history, culture, politics, and the business and economic environment of the country. In addition, they were asked to watch a series of related videos. Next, we assigned each student to conduct secondary research and provide a background (three-page synopsis) report that includes appropriate resource links on two businesses we were visiting, along with the related industry. They were to also identify five major issues/questions related to the business operations they could raise during the site visits. These reports were then shared with the rest of the participants. For the Germany trip, groups are created in advance and assigned one location for which they must create a "location cheat sheet" for the other participants which highlights the location's historical, cultural, and business background. The group distributes their cheat sheet and gives a presentation when they arrive at that location. In addition to prescribed assignments related to the culture of the country the students will visit, which may also include self-help quizzes about cultural differences, we ask speakers to come and share cultural and business observations. In the case of our Malaysia/ Singapore and Chile trips, we notice that besides being receptive to "expert" speakers from business and academia, students tend to react very positively to resource persons, such as their counterparts who have lived in that country or are from those countries. Also, cultural simulations can be used very effectively to give students an understanding of the power of cultural conventions. Proper preparation and continuous input can help students understand that, for example, in some countries, people don't drive on the "wrong" side of the road - they drive on a "different" side of the road. Students also ask for more opportunities for informal get-togethers sufficiently in advance of the actual trip. We have some exercises and games that can be used during orientation sessions to "break the ice" and to know more about each other's interests and talents. This is useful because it promotes a feeling of camaraderie and family among participants to look after each other while overseas. In addition to face-to-face engagements, social media groups can be formed to facilitate interaction within the group. For instance, the Germany trip Facebook page though less informal - has often become a forum for questions, communications, and concerns. 


\section{Health And Safety Information}

We also include a session devoted to health and security issues with knowledgeable professionals from the university health center who advises students of such things as needed vaccinations, hygiene, food and sanitation care for the particular sites that they would visit and the necessary insurance for such things as medical issues that may develop while overseas. It is a good policy to require all students to purchase medical insurance as part of the trip. This can be incorporated into the cost of the trip and is usually quite cheap, typically a few dollars per day. There are also service providers who will give information on safety issues and concerns in the country of interest. These services also offer to send e-mail alerts to students and parents. We would advise caution before subscribing to one of these services. In some cases, the service merely collects and distributes news articles without having any "local knowledge." As a result, the alerts can be overly dramatic and cause unnecessary alarm for parents. However, it is necessary to have well-informed program leaders on student safety issues and protection.

\section{Behavioral Policies}

One of the main reasons that faculty members avoid developing and leading SSA programs is the concerns regarding behavioral issues that can arise. There are no methods to guarantee a problem-free experience, but there are some general guidelines. If the "right" students are selected, then the potential problem is significantly reduced. The challenge is picking the "right" students. While there is no empirical research to support this, in general, we look at finding students with good GPAs and those that have strong recommendations from faculty colleagues. Students who complete the application process in a timely fashion are viewed as being more responsible and are frequently given preference. Finally, personal interviews or in-formal interactions can help in the selection process. As the group must be together for two to three weeks straight, sharing hotel rooms, meals, transportation modes, activities and such, special attention should be paid to those that quite simply "play well with others." It only takes one or two individuals that lack social skills to suck a great deal of energy out of the group. Thus, while GPA is often a strong predictor of behavioral elements, it provides little evidence of social skills. Probably the most important factor in maintaining proper behavior is setting the expectations for the students. The first chance to do this is when interviewing the candidates. This should be followed up during the orientation meetings. It should be clear what is expected - respect for each other, respect for the facilities that are being used, and respect for the professional hosts. For example, on the Australia trip, the provider uses high-quality serviced apartments. We make clear to the students that they are not to make noise in the hallways or their rooms, that there are not to be parties in the rooms - as is the policy of the apartment complex - and if they violate this rule and are asked to leave the complex, we will not be responsible for finding alternate housing for them. It is also important to manage the group assembly process firmly. If there are some students who are not on time, other students may feel that they have time to run back to their rooms to get a camera they forgot, etc. This can lead to a cascade of delays and should not be tolerated. Being firm early reduces problems later and we emphasize that students arrive on time and if they don't, they run the risk of being left behind and having their grade adversely impacted. Students also need to be reminded about basic courtesy and consideration for others. For example, groups of students may block passageways in airport terminals or congregate at the landing point of an escalator, and they should be cognizant to avoid such outcomes.

\section{E. Logistics}

It is important to provide students with clear, simple information on critical logistical issues. Students will be overloaded with many details - large and small. It is important to emphasize the critical requirements - passport applications, purchase of airline tickets, visas, etc. - that have the potential to make the student's participation problematic. In practice, most students are not cognizant of the itinerary and should be reminded of the next day's activities on a daily basis. Group dinners provide an excellent opportunity to provide students with important details on the next day's activities and requirements. It is also strongly recommended that a week or two before departure, you contact all of the key individuals and reconfirm the arrangements you have made. This can be important as circumstances may have changed and this last exchange gives you an opportunity to adjust. For instance, on the Germany trip in 2012, the confirmation process with the one hostel uncovered that the hostel had changed management and thus some policies had changed, including whether towels were provided. Last-minute adjustments were made and when the group arrived, the experience was not diminished by something as simple as a 
lack of towels. It was easily adjusted in advance and would have been less convenient and more expensive to handle upon arrival. It is recommended that all documents related to the trip logistics (e.g. hotel confirmations, restaurant reservations, tour/visit confirmations) be put together in a binder and three copies of the binder be created. One stays home with someone easily reachable within the college or study abroad office, and the others accompany the two faculty members on the trip. This provides a fail-safe record if the primary faculty champion becomes ill or injured. In that case, the assistant faculty member could step in and keep the trip moving forward.

\section{On-Site Activities And Issues}

Once the SSA journey begins, several on-site activities need to be managed and executed. These include initial orientation meeting, daily meetings and updates, group tours, and host interactions.

\section{A. Initial Orientation Meeting}

At a predetermined time and location, all of the students and leaders get together to discuss the plans and activities for the program and explain any changes that have been made since the last pre-departure information. This meeting usually happens shortly after arrival and is often held in a room or lobby in the hotel where the group is staying. In the case of the Australia program, usually all of the students will be arriving as a group. The provider's on-site guide meets the group at the airport and accompanies the group to the accommodations. Because visitors from the U.S. arrive in Australia early in the morning, the rooms are usually not available. The group stows their suitcases in a conference room and the guide leads the group in a range of activities that is primarily designed to keep the students on their feet and active for the day. These activities include visiting ATM machines, a group lunch, and a tour of the city. The group is brought back to the accommodations early evening to check in, take showers, and meet for an arrival dinner. Students are not given enough time for naps on purpose and are encouraged to stay up at least until 9pm - after the group dinner - to minimize the impact of jet lag. For our program in Chile, on arrival, there was a detailed orientation for the participants providing security and safety-related advice, how to contact in an emergency (24 hours), providing a flash card with common phrases in Spanish, etc. Then the group was asked to participate in a version of a competitive scavenger hunt. The participants were divided into groups of four, given a fixed amount of money, and then asked to go to a number of different cultural and historical sites, museums, markets, local eating places, and other key places to visit in Santiago. Points were assigned to bringing back evidence of each of these visits and interactions. The winning group would be given a special prize (turned out to be nice polo shirts identifying them as winners). This "cultural game" turned out to be a huge group pleaser because the participants quickly got acquainted with the subway system, discovered how to get directions, even though they did not speak Spanish, and returned with ideas on which of these places they wanted to return to during their free time. With proper and timely planning, the study abroad program can be conducted more efficiently and effectively. However, unexpected events can occur overseas and the faculty leader(s) have to be deal with these issues. We discuss some of these that we have experienced after discussing our approaches toward conducting these programs.

\section{B. Daily Meetings/Updates}

In addition to the first initial meeting, most days there should be an early gathering to discuss the daily itinerary, as well as an end-of-the-day wrap-up to talk about insights and to remind everyone of the next day's schedule. As mentioned previously, students are not usually good at following an itinerary, no matter how well constructed. It is more effective to provide these details in daily doses. Also, these meetings can be very helpful in reinforcing what was learned today and making observations that the students might have missed.

\section{C. $\quad$ Group Tours And Visits}

Tours generally fall into three categories - business and plant visits, cultural visits and institutional visits. The first program in the itinerary needs to provide a good and transparent overview of the region. In our Malaysian/Singaporean trip, we began with a visit to the U.S. Embassy in Singapore which the group found to be a great start for the program. The embassy had arranged for the commercial staff to provide participants with an overview of business and economic developments and potential business opportunities in Singapore and Malaysia 
and the region in general. In this meeting, interactions were candid and helped identify relevant issues that were explored with the organizations visited later. Other alternatives that have helped include the joint chambers of commerce (e.g. U.S. - Singapore Chamber of Commerce), the local chamber of commerce, or, alternatively, a business/academic resource person who can provide that overview.

In general, we find students to be more engaged when the site visits included plant tours in addition to presentations. The Q \& A sessions are more involved as students have many questions based on the plant tour. Another way to generate quality interaction is for the presenters to ask for the students' opinions about their operation and business. For example, in Chile, one small winery wanted to further expand its sales in North America and worldwide and a simple query from the presenter resulted in a variety of ideas put forth by the participants. For our programs in the Malaysia/Singapore and the Chile programs, we would also ask the students who were responsible for the preparation of the background report on the organization to provide a 15-minute refresher about the company before the visit. We have done this at the hotel before the visit, on the bus trip to the company if time permits, or at lunch when the visit is in the afternoon. Where possible, we request copies of the presentations to be shared with other students in the U.S. In the case of provider-organized programs, a knowledgeable guide usually accompanies the group on cultural visits and plant tours. In the case of the Malaysian/Singapore program, academic colleagues also accompanied us and provided further insights into the country's culture, political climate, and business practices. In addition, students were asked to keep a diary and notes on cultural differences that they observed during business visits and in everyday interactions with the locals.

Often, activities on study abroad programs involve interaction with students and/or faculty at other institutions of higher learning. Our Germany program, in particular, visits three different German universities. At one, a German professor lectures on a relevant topic and this experience concludes with a discussion on the different approaches between the typical German professor and the typical American professor. As the student-professor relationship is very salient to the students, discussing this as a way to highlight broader cultural differences has proven very interesting and popular with the students. The Germany program also includes two, day-long case experiences as described earlier in this paper. These are great experiences for the students from both universities. The faculty champion for this program has found that these days often make the student's top five lists at the end of the program as they really like spending a day interacting with their student counterparts. In both situations, the interactive benefits are stressed above the pure task elements of the case experience and the day concludes with an informal dinner celebration that involves a great deal of hand-shaking and Facebook friending.

\section{Host Interactions}

In the Malaysia/Singapore program, academic colleagues there had organized a reception with students from their university early in the program. Students from those universities easily developed rapport and many became cultural and sightseeing guides and companions for our students. In Chile, our students actually went to student-favored places where they struck up friendships with their counterparts. Many of these students still remain in touch with each other through social media, such as Facebook. Most students were very eager to try out local food, including exotic fare (e.g. Durian fruit in Malaysia/Singapore). In fact, when providers wanted to direct them to American eating places, they preferred not to go there. In general, eating places that offer local food tend to also be less expensive. Some students at the end of the program decide to stay longer, usually to travel within the country and neighboring countries. In both our Malaysia/Singapore and Chile programs, we had students who made arrangements in groups of two or more to extend their stay. This personal option is better than having an extended program, mainly because of the additional costs that would be otherwise incurred by all.

\section{Post SSA Activities And Grading}

It is important to establish early on that just because students make the SSA trip that their program requirement and learning is complete or that they would be guaranteed a high grade for the course. Postparticipation discussions, reflections, and completion of written assignments after the trip has occurred are essential. In addition, participation and behavior-related components should be part of the grading to ensure attentive behavior during the program. Clearly defined expectations up front will mean fewer problems when the time comes for assigning grades. 
One way to crystalize the learning for the students is to have them complete a reflection paper. For instance, for the Germany program, they are asked to reflect on the five most critical business and cultural lessons they learned and how they would incorporate these lessons into a future career as a globally-oriented business person and, finally, offer a review of the program, including their top five and bottom five lists for the trip. This final element also offers the faculty champion feedback on the quality of the program experiences from the students' perspective. For our recent Malaysia/Singapore and Chile programs, we got together at a faculty leader's home for an evening discussion. This was four weeks after the return so that participants had time to reflect on different components of the overseas program. With a faculty leader as the moderator, the discussion focused around lessons learnt based on differences in the conduct of business in those countries, cultural differences experienced, and their implications for conducting business - both domestically and abroad. The discussion also focused on how domestic counterpart firms can benefit from business applications observed in the host country. A complement to a reflection paper is for a student to maintain a blog during and after the trip. This has the advantage of documenting the trip for the student and providing something for them to remember for some time afterward. It also allows them to communicate with friends and family and provides another useful feedback source to potential students exploring SSA. To make this effective, it is necessary to set firm criteria on what is expected. First, it should be expected that a minimum number of words be posted on the blog during the trip - at least 400 is recommended - along with a minimum number of pictures/videos per day - at least three are recommended. Second, emphasis should be placed on having serious content, especially content that has them reflect on what they have seen and what they learned. For the Australia trip, the book "Down Under" by Bill Bryson is required reading before the trip and is used as a model for the blog content.

\section{STEP 4: EVALUATION}

The final step in the process is evaluating the program and determining whether objectives were achieved and what changes should be made to the program when it is offered in the future. Evaluations are most effective if done as soon as possible after the trip when memories are fresh.

These evaluations should come from students, faculty and program leaders, and service providers.

\section{A. Student Evaluations}

The normal course evaluation form can be used, but more useful are specific questionnaires with questions regarding the program - from the pre-departure orientation to the post-program briefing - using both qualitative and qualitative metrics. Currently, program-specific questionnaires have been developed individually by each faculty leader, using both formal and informal instruments. Participant feedback can be very useful in developing marketing materials for the program in the future.

\section{B. Faculty Evaluations}

The faculty leaders should review all of the components of their program. Particular attention should be paid to an assessment of the educational value of the business and cultural visits. Attention should also be paid to the professional and personal conduct of the students, the extent of engaged participation by the students, unexpected events, and how these were handled. The latter includes a range of problems that can emerge. For example, students losing passports (local consular officers help), missing flight connections on the way to the site, getting lost on site (flash cards with hotel address in local language and phone numbers), getting scammed in currency exchanges or by taxi drivers, getting sick (getting competent medical help and doctors, hospitals in proximity), some feelings of loneliness (need for "buddy systems"), not getting along with the roommates (allowing changes on site), suffering "culture shock" (exotic foods, differences in standards of hygiene, beggars, handling intrusions of personal space, etc.). An account of these allows for continuous improvement in how these problems can be avoided or best handled.

Gauging feedback from prior evaluations and experiences can help. We encourage brown bag and other informal sessions in the fall semester where faculty leaders of the various summer short-term study abroad programs can get together and share their experiences with others. In addition, these experiences are also shared with 
colleagues running Study experiences in other universities. For the Malaysia/Singapore program, we had three Skype sessions dissecting and getting feedback from academic counterparts who helped to arrange these programs. Our SSA faculty champions also provide a synopsis of their experiences to the college's International Business Education Committee every fall semester. In addition, every two years we have a study abroad roundtable in the college where the faculty leaders provide counsel and tips to faculty interested in leading SSA programs.

\section{Provider Evaluations}

If a provider is used, a critical assessment of the provider's services should be performed. This assessment should include all aspects of the provider's services, including the quality of the business visits, the quality of the presenters during those visits, the level of interactions, the relevance of tours for understanding global business concepts, the value organized cultural visits, the level of knowledge of the assigned guides, the ability to respond to diverse queries, the ease of rapport with the guide, an assessment of the accommodations, the level of service (expected vs. realized), cooperativeness of hotel/hostel staff, quality of meals, the ease and comfort of different modes of transportation, congruence between the expected versus realized schedules, etc. It helps to also ask the providers and academic counterparts who assist with arrangements for their observations about the conduct and interactions of students on the trip. In addition, management and staff at hotel, restaurants, transportation companies, and others should be consulted to determine perceptions of the students and the activities that they oversaw.

\section{CONCLUSION}

In organizing and conducting the SSA, one must never lose sight that the objective of the trip is to provide an academic cross-cultural experience rather than a group vacation. Thus, careful attention should be paid to the academic value and rigor of the trip. It is vital to have a faculty champion and other critical support staff. A faculty director on a SSA can't have a distant, aloof, uninvolved relationship with students as these characteristics translate very poorly to a SSA environment. He/she needs to have a passion for and rapport with students and may be expected to have many roles, including being a faculty advisor, tour guide, den mother, social worker, and task master. Faculty should not underestimate the time required. There will be some who see this as an attractive way to teach a class considering the short time duration of the class. However, the reality is that the nature of the trip requires a 24/7 focus and, more importantly, the planning and marketing of the SSA create a much greater time commitment for the faculty member. Pre-work, in-country work, and post-experience work should all be developed fully and professionally with a lot of careful thought so that the short-term nature of the program does not equal a watered down academic experience. This is also important as you sell this trip to administrators and colleagues who might see the trip as a glorified vacation for all. A SSA trip can be effectively and efficiently developed and successfully executed within the SSA framework proposed in this paper consisting of four stages - Planning, Marketing, Conducting, and Execution. A series of strategies and tactics, coupled with a proactive approach to dealing with anticipated and actual SSA-related problems, can significantly enhance the educational and cultural experience for participants, the positive benefits of which can have far and long-term effects, though the SSA is considered a short-term duration program.

\section{AUTHOR INFORMATION}

Dr. James A. Eckert is Co-Director of the Sales \& Business Marketing Program at Western Michigan University. He specializes in teaching, research, and consulting in the areas of selling and negotiation internationally. Dr. Eckert is heavily involved in study abroad efforts at WMU and is an adjunct faculty member at Universitaet Paderborn in Germany.

Dr. Mushtaq Luqmani is a Professor of Marketing and International Business and currently serves as the Chair of the Marketing Department at Western Michigan University. He obtained his Ph.D in Marketing from Michigan State University. He has published over 80 articles in scholarly journals and venues, notably in the area of International Marketing. As a Co-Director of several U.S. Department Education Grants, he has coordinated a number of projects on internationalizing the university curriculum. He has consulted for domestic and multinational companies and has served as a United Nations TOKTEN Expert. 
Dr. Stephen Newell is a Professor of Marketing at Western Michigan University. He has a Ph.D from Florida State University, an MBA from Indiana University and an undergraduate business degree from Michigan State University. He has developed global student exchange relationships between WMU and a number of universities in Europe and Japan. In addition, he has published articles in variety of journals including: The Journal of Advertising, Psychology \& Marketing, and The Journal of Business Research.

Dr. Zahir A. Quraeshi is the G.W. Haworth Chair of Global Business and Director of the Global Business Center at the Haworth College of Business, Western Michigan University. He has been a Visiting Professor at universities here and abroad and was the Tan Sri Noah Distinguished Chair of Business at University Kebangsaan Malaysia (1995 to 1996). He teaches international business and has received the WMU Alumni Teaching Excellence award. He has published numerous articles in professional journals and was the Founding Editor of the Journal of AsiaPacific Business. E-mail: zahir.quraeshi@wmich.edu (Corresponding author)

Dr. Bret Wagner has a Ph.D. in Operations Management from Michigan State University. He has conducted numerous short-term study abroad programs and serves currently as the chair of the International Education Council at Western Michigan University. Dr. Wagner teaches courses in production planning and scheduling, quality management, business process management and enterprise systems. He is the co-author of the textbook Concepts in Enterprise Resource Planning.

\section{REFERENCES}

1. $\quad$ Albers-Miller, N. D., Prenshaw, P. J., \& Straughan, R. D. (1999). Student perceptions of study abroad programs: A survey of us colleges and universities. Marketing Education Review, 9(1), 29-36.

2. Angulo, S. K. (2008). Identity change in students who study abroad. (Doctoral dissertation, The University of Texas at Austin).

3. Black, T. H., \& Duhon, D. L. (2006). Assessing the impact of business study abroad programs on cultural awareness and personal development. Journal of Education for Business, 81(3), 140-144.

4. Brokaw, S. C. (1996, Fall). Planning, organizing, and executing short-term international exposures for U.S. students of marketing and business: An alternative method. Marketing Education Review, 6, 87-93.

5. $\quad$ Carlson, J. S., Burn, B. B., Useem, J., \& Yachimowicz, D. (1991) in E. G. Barber \& B. B. Burn (Eds.), Study Abroad: The Experience of American Undergraduates in Western Europe and the United States (pp. 1-69). New York, NY: Council on International Educational Exchange.

6. $\quad$ Carlson, J. S., Burn, B. B., Useem, J., \& Yachimowicz, D. (1990). Study abroad: The experience of American undergraduates. New York, NY: Greenwood Press.

7. Carlson, J. S., \& Widaman, K. F. (1988). The effects of study abroad during college on attitudes toward other cultures. International Journal of Intercultural Relations, 12(1), 1-17.

8. Carsello, C. \& Creaser, J. (1976). How college students change during study abroad. College Student Journal, 10(3), 276-278

9. $\quad$ Clarke, I., Flaherty, T.B., Wright, N.D., \& McMillen, R.M. (2009). Student intercultural proficiency from study abroad programs. Journal of Marketing Education, 31(2), 173-181.

10. Curran, S.J. (2007). The career value of education abroad. International Educator, 16, 48-52.

11. DeJong, P., Schnusenberg, O., \& Goel, L. (2010). Marketing study abroad programs effectively: what do American business students think? Journal of International Education in Business, 3(1/2), 34-52.

12. Drews, D. R. \& Meyer, L. L. (1996). Effects of study abroad on conceptualizations of national groups, College Student Journal, 30(4), 452-462.

13. Duke, C. R. (2000). Study abroad learning activities: A synthesis and comparison. Journal of Marketing Education, 22(2), 155-165.

14. Gammonley, D., Rotabi, K. S., \& Gamble, D. N. (2007). Enhancing global understanding with study abroad: Ethically grounded approaches to international learning. Journal of Teaching in Social Work, 27(34), 115-135.

15. Golay, P. A. (2006). The Effects of study abroad during college on attitudes toward other cultures. (Doctoral dissertation, Florida State University).

16. Gonyea, R. M. (2008, November). The impact of study abroad on senior year engagement. Paper presented at Annual meeting of the association for study of higher education. 
17. Hadis, B. F. (2005). Gauging the impact of study abroad: How to overcome the limitation of a single-cell design. Assessment and Evaluation in Higher Education, 30(1), 3-19.

18. Hilton, G. (2007, November 01). Becoming culturally fluent: understanding the variances of culture across Asia can enhance business and communication. Communication World, Retrieved from http://www.highbeam.com/doc/1G1-171659325.html

19. Hutchins, M. M. (1996). International education study tours abroad: Students' professional growth and personal development in relation to international, global, and intercultural perspectives. (Doctoral dissertation, Ohio State University).

20. Institute of International Education. (2011). "Open doors, fast facts." Open Doors Report on International Educational Exchange. Retrieved from http://www.iie.org/opendoors

21. Kaufman, P. A., Melton, H. L., Varner, I. I., Hoelscher, M., Schmidt, K., \& Spaulding, A. D. (2011). Alternative approaches for educating future global marketing professionals: A comparison of foreign study and research-intensive marketing programs. Journal of Marketing Education, 33(3), 285-294

22. Kitsantas, A. (2004). Study abroad: The role of college students. College Student Journal, $38(3), 441-452$.

23. Koernig, S.K. (2007). Planning, Organizing, and Conducting a 2-Week Study Abroad Trip for Undergraduate Students :Guidelines for First-Time Faculty Journal of Marketing Education, 29 (3), 210 217

24. Langley, C. S., \& Breese, J. R. (2005). Interacting sojourners: A study of students and studying abroad. Social Science Journal, 42(2), 313-321.

25. Lincoln Commission. (2005). Global competence and national needs: One million Americans studying abroad. Final Report from the Commission on the Abraham Lincoln Fellowship Program, Washington, DC.

26. McCabe, L. T. (1994). The development of a global perspective during participation in semester at sea: A comparative global education program. Educational Review, 46(3), 275-286.

27. Milstein, T. (2005). Transformation abroad: Sojourning and the perceived enhancement of self-efficacy. International Journal of Intercultural Relations, 29(2), 217-238.

28. Mistretta, W. (2008). Life-enhancing: An exploration of the long-term effects of study abroad. (Doctoral dissertation, State University of New York at Buffalo).

29. NAFSA (2003). Securing America's future: Global education for a global age. Association of International Educators. Retrieved February 23, 2011 http://www.nafsa.org

30. Norris, E.M., \& Gillespie, J. (2009). How study abroad shapes global careers: Evidence from the United States. Journal of Studies in International Education, 13, 382-397.

31. Quraeshi, Z.A., Luqmani, M. \& Veeck, A. " Advancing the Participation of Business Students in Study Abroad Programs" Global Journal of Management and Business Research, 12 (11),81-92.

32. Schuster, C. P., Zimmerman, R. O. Schertzer, C. B., \& Beamish, P. W. (1998). Assessing the impact of executive MBA international travel courses. Journal of Marketing Education, 20(2), 121-132.

33. Thomlison, D. T. (1991). Effects of a study-abroad program on university students: Toward a predictive theory of intercultural contact. University of Evansville, Evansville, Indiana.

34. Toncar, M. F., \& Cudmore, B. V. (2000). The overseas internship experience. Journal of Marketing Education, 22(1), 54-63.

35. Toncar, M.F., Reid, J.S., \& Anderson, C.E. (2005). Perceptions and preferences of study abroad: Do business students have different needs? Journal of Teaching in International Business, 17, 61-80.

36. Williams, T.R. (2005). Exploring the impact of study abroad on students' intercultural communication skills and adaptability and sensitivity. Journal of Studies in International Education, 9, 356-371. 


\section{NOTES}

